\title{
Parental awareness and cascade screening of Thalassaemia in Sri Lanka
}

\begin{abstract}
A strategy to prevent new births with thalassemia major in countries where abortion is illegal is to screen the at risk population for the carrier state and advocating "safe marriages". One of the highest risk groups to have thalassemia gene are the relatives of individuals with a child with 'Thalassemia major'. 'Cascade screening' of such relatives is an effective way to initiate and precede a much wider population screen. We wanted to identify the level of awareness of disease transmission and the extent to which cascade screening was already happening in Sri Lanka. 200 parents of children with transfusion dependent thalassemia attending the Thalassemia units at Ragama and Kurunegala were interviewed. Seventy three percent fathers and $9 \%$ mothers knew there carrier state. 59(64.1\%) fathers and 98(88.1\%) mothers knew their carrier state has caused the illness to the child. Mother had 382; fathers had 291 siblings and those siblings had 714 and 610 children respectively. $40(10.8 \%)$ of maternal siblings and $15(5 \%)$ of the paternal siblings had been screened for thalassemia. Only $48(6.72 \%)$ of maternal side children and $23(3.77 \%)$ of paternal side children has been screened. Wider awareness and a screening programme targeting those high risk populations must be launched without delay because prevention is better both for the patient aspect as well as the cost aspect to the government. More studies probably qualitative needed to evaluate the individual factors for above results
\end{abstract}

Keywords: safe marriages, thalassemia, cascade screening, implementation, population
Volume 5 Issue I - 2017

\author{
Nilanga Nishad AA,' Premawardhena AP² \\ 'Biyagama Ministry of health, Sri Lanka \\ ${ }^{2}$ Department of Clinical Medicine, University of Kelaniya, Sri \\ Lanka
}

Correspondence: Nilanga Nishad AA, Medical officer of health, Biyagama, Ministry of health, No I22/A/3, Maharanugegoda, Ragama, Sri Lanka, Tel 0947/8331470, Email aanilanga@gmail.com

Received: May 25, 2017 | Published: July 17, 2017

\section{Introduction}

In countries such as Sri Lanka; where abortion is illegal, strategies to prevent new births with thalassemia major is limited to screening the at risk population for carrier status and advocating 'safe marriages'. The 'safe marriage' strategy ensures that neither or only one of the partners is a beta-thalassemia carrier at marriage or when the decision to bear a child is made. Cascade screening of relatives of thalassemia major patients is considered as a way to initiate and precede a much wider population screening of thalassemia carrier status. ${ }^{1}$ Cascade screening involves the screening of all immediate relatives of both (parent) arms of a thalassemia major child. Yet, some scientists believe that we can never reduce the thalassemia burden unless a policy change favouring induced abortions occurs. We tried to identify the level of awareness of disease transmission among parents of thalassemic children and to estimate the extent to which cascade screening had already penetrated Sri Lanka before the universal screening program began.

\section{Methods}

We recruited 200 parents of transfusion dependent thalassemia patients from two main and two peripheral thalassemia centres in Sri Lanka using stratified random sampling and interviewed both mother and father. A self administered questionnaire was developed in
Sinhala language to collect data on parents' knowledge on their carrier status and to assess the extent to which carrier screening had taken place in their families. Review of medical records was conducted in addition to the interviews. Data were analyzed for percentages and comparisons were done to determine which arm of the family was better screened. ${ }^{2}$

\section{Results}

There were 100 parent couples representing 100 transfusion dependent thalassemia children. The mean age of thalassemic children was 13years $(\mathrm{SD}=7.3)$. In the assessment of knowledge regarding the thalassemia, $91 \%$ mothers and $73 \%$ of fathers were aware of their carrier status. Eighty eight percent of mothers and $64 \%$ of fathers knew that their carrier state had predisposed their children to the illness. Table 1 shows the extent to which siblings of the parents and the nuclear family members of those siblings had been screened for thalassemia. As in Table 1, significantly higher number of siblings from the mothers' side $(10.8 \%)$ had been screened for thalassemia than from the fathers' side (5\%). More children of siblings from the mothers' arm $(6.7 \%)$ were screened than those of the fathers' $(3.8 \%)$ as well. Interestingly, more spouses of siblings from the fathers' arm $(6 \%)$ had been screened than the mothers' arm (3.6\%). All these differences were statistically significant at $1 \%$ level.

Table I Status of thalassaemia screening among relatives of parents with thalassaemia

\begin{tabular}{lllll}
\hline Parent & Mother's arm & Father's arm & Total & Significance \\
\hline Number of siblings & 382 & 297 & 679 & \\
Number of siblings screened & 41 & 15 & 56 & $P<0.01$ \\
Percentage & $10.80 \%$ & $5 \%$ & $8 \%$ & \\
\hline
\end{tabular}




\begin{tabular}{lllll} 
Table Continued.... & Mother's arm & Father's arm & Total & Significance \\
\hline Parent & 334 & 248 & 582 & \\
\hline Number of spouses of the siblings & 12 & 15 & 27 & $P<0.01$ \\
Number of spouses screened & $3.60 \%$ & $6 \%$ & $4.60 \%$ & \\
Percentage & 714 & 610 & 1324 & \\
Number of children of the siblings & 48 & 23 & 71 & $P<0.01$ \\
Number of children screened & $6.70 \%$ & $3.80 \%$ & $5.30 \%$ & \\
Percentage & & & & \\
\hline
\end{tabular}

\section{Discussion}

In Sri Lanka, there seem to be deficiencies at present in the screening of relatives of patients with thalassemia. Unfortunately, locally or internationally there are no other published studies to compare these findings with. A probable reason for poor level of penetration in cascade screening could be the social stigma, limiting the parents from divulging their child's thalassemic condition even to their closest relatives. According to Sangani et al., ${ }^{3} 20 \%$ of families with thalassemia children had expressed having had unfavourable reactions from their relatives. Non availability and non-affordability of screening facilities was also described as a limiting factor identified in India. These same reasons may have affected the Sri Lankan populations as well.

\section{Conclusion}

However, wider awareness and screening programs targeting those high risk populations have become the biggest hope in reducing new births with beta and $\mathrm{E}$ beta thalassemia, where abortion is not only considered illegal, but also a sin. This letter also highlights the deficiencies of cascade screening as a program to reduce the disease burden, and may justify implementation of programs such as essential pre marital thalassemia screening.

\section{Acknowledgements}

None.

\section{Conflict of interest}

The author declares no conflict of interest.

\section{References}

1. Cao A, Galanello R. Effect of consanguinity on screening of thalassemia. N Engl J Med. 2002;347(15):1200-1202.

2. Saxena A, Phadke SR. Feasibility of thalassaemia control by extended family screening in Indian context. J Health Popul Nutr. 2002;20(1):3135

3. Sangani B, Sukumaran PK, Mahadik C, et al. Thalassemia in Bombay: The role of medical genetics in developing countries. Bull World Health Organ. 1990;68(1):75-81. 